\title{
JARDINES DEL CUERPO QUE SE FRAGMENTA
}

\section{Tatiana Herrera Ávila}

\begin{abstract}
RESUMEN
En este artículo, se presentará un análisis en torno al tema de la fragmentación del cuerpo de la amada que hace el sujeto enamorado en su discurso amoroso. Para ello, se tomará como eje central el caso de la novela Los jardines secretos de Mogador del escritor mexicano Alberto Ruy Sánchez, y se partirá fundamentalmente de los postulados teóricos que Roland Barthes expone en Fragmentos de un discurso amoroso, aunque también se tomarán como puntos de partida algunas nociones centrales del psicoanálisis freudiano, tales como la imposibilidad de la completud y el cuerpo como límite del sujeto.

Palabras clave: Los jardines secretos de Mogador, Ruy Sánchez-Alberto, literatura latinoamericana, cuerpo, fragmentación.
\end{abstract}

\begin{abstract}
This article will present an analysis on the subject of the fragmentation of the beloved's body that the lover does in his romantic speech. For this, it will take as a central axis the case of the novel Los Jardines Secretos De Mogador (The Secret Gardens of Mogador) by the Mexican writer Alberto Ruy Sanchez, and it will fundamentally take from the theoretic application that Roland Barthes exposes in A Lover's Discourse: Fragments, it will also take as starting points some central notions of freudian psychoanalysis, such as the impossibility of completeness and the body as a limit to the subject.

Key words: Jardines secretos de Mogador, Ruy Sánchez-Alberto, latinamerican literature, body, fragmentation.
\end{abstract}

Cuántas veces he ido en hora temprana a los jardines: las ramas me recordaban la actitud de los amantes. ¡Qué hermosas se mostraban cuando el viento las entrelazaba como cuellos! Las rosas son mejillas; las margaritas, bocas sonrientes, mientras que los junquillos reemplazan a los ojos.

Ibn Hafs al-Yaziri

Lic. Tatiana Herrera Ávila. Profesora de Literatura y Humanidades. Universidad de Costa Rica. Correo electrónico: tatiana.herrera@ucr.ac.cr

Recepción: 02- 02- 2012

Aceptación: 19- 04- 2012 


\section{Preámbulo mítico-erótico (Del Paraíso al texto)}

Entrar en un universo literario a veces es caminar laberintos que se intercomunican y entretejen entre sí. A menudo, el acto de leer es como adentrarse en diversas estancias, con la promesa de encontrar el minotauro y solo nos es permitido salir si seguimos la hebra de la madeja que una buena y desconocida Ariadna nos ha dejado como clave para la interpretación.

Pero, a veces, la deriva del lector se vuelve aún más intrincada, pues entre todas las callejuelas que recorre únicamente se perciben incitaciones y provocaciones que confunden y simulan una semejanza entre el discurso literario y el discurso erótico. El deseo, que ya Aristóteles señalara como el único principio motriz en su Ética a Nicomaco, ese móvil de todos los crímenes, ese motor de todas las aventuras aparece, entonces, en el lugar del minotauro y nos llama como un eco lejano hacia el centro del laberinto/texto. Hay por lo tanto preguntas y más preguntas, problemas, enigmas y misterios que seducen y motivan a seguir siempre más allá, buscando un mítico oráculo que nos indique la salida. De ahí que hablar del placer del texto, no es solo teorizar, si no dar cuenta de una poética erótica, esto es una po/e/ ró/tica (Barthes 1996: 32).

El lector deambula, por decirlo de otra manera, entre los diversos aposentos que conforman el laberinto textual a la manera de un soñador o de un enamorado guiado por su deseo y mientras transita también va construyendo, leyendo y yendo.

Con la metonimia por brújula, de la misma forma en que del texto puede emanarse el laberinto y de este el deseo, puede pensarse en cuerpo cuando se piensa en laberinto, locus eterno del deseo. Y este cuerpo/laberinto puede encallar en jardín porque muchos huertos son como laberintos, especialmente los de herencia mozárabe. Los jardines árabes (y también en la tradición judeocristiana) son reminiscencias del Edén, microcosmos del que nos han expulsado, pero jardín de las delicias al que, Dios nos ha prometido, regresaremos. (Chevalier 1999: 603).

Así, puede asistirse al sortilegio que presenta Alberto Ruy Sánchez en su novela Los jardines secretos de Mogador. En ella, la literatura y la pasión se yuxtaponen en caligrafías y palimpsestos casi indescifrables para constituir un texto que es cuerpo de la amada, que es jardín de las delicias y laberinto del deseo. Penetrar por las encrucijadas y bifurcaciones que nos tiende esta novela es el deseo que provoca esta urdimbre, en la cual iré descubriendo esos jardines secretos que son los fragmentos del cuerpo de Jassiba, la amada del protagonista, con la lupa esclarecedora del psicoanálisis, tanto lacaniano como freudiano, y de algunos de los fragmentos del discurso amoroso de Roland Barthes. Se diría que este ejercicio de lectura es más que evidente y sería justo si no hubiera una relación sistémica y metonímica entre los diversos niveles que abordaré, lo cual le otorga una dimensión insospechada a la novela.

\section{Fronteras}

El texto que nos ocupa Los jardines secretos de Mogador. Voces de tierra corresponde a la tercera de un quinteto de novelas (Los nombres del aire; En los labios del agua; Los jardines secretos de Mogador, voces de tierra; La mano del fuego y Nueve veces el asombro) 
que su autor Alberto Ruy Sánchez (1951) ha ubicado en la ciudad árabe de Mogador, hoy denominada Essaouira, aún cuando él mismo es mexicano. Si este hecho no hubiera sido objeto de discusión por gran parte de la crítica y motivo de una larga defensa que Ruy Sánchez ha debido llevar a cabo, no sería pertinente mencionarlo. No es posición de quien escribe pensar que la literatura deba responder únicamente y exclusivamente a la identidad geográfica del autor, y de hecho parece insostenible (desde la muerte del autor, así como desde contextos como la globalización) la idea de una literatura nacional, aunque es una polémica vieja que en un eterno retorno siempre surge. Así las cosas, y a grandes rasgos, me referiré a lo que ha señalado su autor en relación con este punto, porque sus palabras son elocuentes y categóricas:

\begin{abstract}
Me resulta completamente ajena y hasta ofensiva la idea de una literatura determinada absolutamente por un territorio geográfico o, peor aún, geopolítico. ¿Tiene fronteras la literatura? ¿No es parte de su naturaleza romper las fronteras de lo conocido para mostrarnos dimensiones de la vida que otros géneros no alcanzan a iluminar? ¿Cómo se forma la identidad de una literatura? ¿Es el pasado lo que cuenta o el presente? El pasado marca al presente pero a la vez es reinventado por el presente. Somos hijos de multiples [SIC.] pasados tanto como lo somos de nuestro propio tiempo. Y la literatura explora esta dinámica, no es pasiva receptora de aquello que la precede, es mirada aguda que se mueve en 180 grados. (Ruy Sánchez 2000)
\end{abstract}

Ruy Sánchez señala ciertamente que la literatura no está determinada por la geografía ni por la identidad, no obstante, a modo de defensa para su aparente desarraigo y exotismo tiene una explicación más que justa y que aplica para cualquier escritor y para cualquier lector, sobre todo en América Latina, porque si resulta que el texto está determinado por la identidad de su autor, ¿debería el lector entonces dedicarse más que nada a leer textos que coincidan con su identidad también? Es claro que no.

A pesar de ello, el mexicano por nacimiento que es nuestro escritor se ha visto obligado, como decía, a justificarse y lo ha hecho desde su calidad de mestizo, pero más aún como heredero de esa cultura árabe que sin duda nos llega a todos los latinoamericanos por intervención española. En este sentido, detalla el autor, en uno de sus muchos ensayos, "Escribir en las fronteras del cuerpo", la condición histórica y cultural de mezcla que signa tanto a México (y a Latinoamérica) como a muchos de los países árabes en relación con los españoles, y declara:

El pasado cultural que une a México con Marruecos, al ser ambos países nietos de la cultura arábigo andaluza, nos permite hablar de una frontera cultural que vale la pena explorar para romperla o disolverla. (Ruy Sánchez 2000)

Se refiere de esta forma a la riqueza étnica e identitaria propias de nuestras poblaciones, dando cuenta del complejo proceso de construcción de identidades que se ve multiplicado cuando el sujeto emigra a otros parajes, como es su caso, pues él estudió y vivó por años en Francia, en Italia y Marruecos. Cita, además, la gran riqueza cultural andaluza que fue dominante en los conquistadores y colonizadores de México, y en general de Mesoamérica. También se refiere, unido a lo anterior, a la hibridación lingüística entre el árabe y el español, y a los vínculos existentes entre el mundo árabe y el nuestro a través de prácticas tan variadas como la cerámica o los textiles, y pone de manifiesto las asombrosas semejanzas geográficas que existen entre algunas partes de México y Marruecos, particularmente en Mogador. Todo ello sirve para que quede fuera de toda discusión el hecho de que la producción de Ruy Sánchez responde a determinaciones culturales e históricas incuestionables, pero más aún se fundamenta la ausencia de exotismo en dicha producción. 
Dicho lo anterior, cabe mencionar que -más allá de la problemática nacionalista- la crítica que se ha ocupado de la producción de Ruy Sánchez abunda en análisis estructurales y espaciales, postulando como imágenes organizadoras de los textos figuras tan disímiles como las espirales, las catedrales, los tatuajes, los caleidoscopios, los azulejos. Esto es comprensible si se toma en cuenta que todas las novelas en cuestión abundan en imágenes espaciales, y trata a Mogador, la ciudad del deseo, como un lugar ciertamente imaginario, pero tan concreto como el cuerpo de las protagonistas, hecho que atañe directamente a esta disertación.

Particularmente, Los jardines secretos de Mogador. Las voces de la tierra se publicó en el 2001, en una edición de Alfaguara que incluye además caligrafías de Hassan Massoudy. El relato se centra en Jassiba, una bella y misteriosa mujer que ha perdido a su padre nueve meses antes. Al inicio del texto, el narrador conoce a Jassiba y entablan una apasionada relación. Ella queda embarazada y, en ese momento, su cuerpo y su deseo empiezan a cambiar, a demandar más. El narrador es incapaz de seguirla en este despertar, por lo que ella le pone un ultimátum: no harán más el amor a menos que él le traiga cada noche un jardín secreto nuevo que haya en la ciudad, tarea casi imposible dado que en Mogador ya casi no hay jardines. Así, a modo de una Sherezada inversa, intertexto explícito en la novela, cada jardín que él descubre para Jassiba es un fragmento que lo lleva hacia el deseo de ella, más aún lo ayuda a recuperar pedazos de ella, porque, tal y como se verá, el cuerpo de la amada es siempre fragmentado, nunca alcanzado en su totalidad.

De forma semejante, debo hacer hincapié en que, como se observa, el tema de los jardines es central y eso inserta al texto en la tradición del rawdiyyat, o poemas jardines desarrollados durante la ocupación árabe de España en Andalucía. Cabe apuntar que si bien el texto no pertenece estrictamente al género poético (pues es una novela), sí abunda en imágenes poéticas, al nivel de que se podría clasificar, si se quisiera, como prosa poética ${ }^{1}$, y así mismo se percibe la cercanía con el otro género gemelo: el nawriyyat o poemas flores.

Su estructura se compone de cuatro "espirales" o partes así denominadas en el texto. La primera se titula "La búsqueda sonámbula de una voz", la segunda "Jardines a flor de piel", la tercera "Jardines del instante" y la cuarta "Jardines íntimos y mínimos". Cada espiral consta, a su vez, de nueve partes excepto la tercera que está constituida solo por una parte. Además, cierra la novela una "Mínima nota jardinera y agradecimientos" y las caligrafías de Hassan Massoudy, que se han venido intercalando entre cada espiral. Si bien esta distribución no es casual y se haya más que motivada dentro del texto, no compete a este trabajo establecer o puntualizar dichas determinaciones, y más bien nos concentraremos en el espiral primero, porque en los otros simplemente el asunto que aquí compete, la fragmentación del cuerpo de la amada, se reitera una y otra vez.

\section{La mirada del cuerpo}

Antes de entrar en el análisis propiamente de la fragmentación del cuerpo de Jassiba en la novela, se hace necesario puntualizar en los elementos teóricos que servirán de lente en esta interpretación.

Para ello, debe hacerse referencia antes que nada a Freud y a sus abordajes al tema del deseo y al de la mirada, pues el que desea y ama, mira a su objeto de deseo y, como señala Freud, hay formas de mirar en las que aflora lo inconsciente. Interesa particularmente la lectura que hace el psicoanalista de la Gradiva, pues la novela Gradiva: una fantasía 
pompeyana, del escritor alemán Wilhem Jensen, publicada en 1903, le sirve al psicoanalista para explorar varios temas como la neurosis, los sueños y el deseo.

En este artículo, Freud retomará el tema de la interpretación de los sueños, pero desde otro ángulo. La novela como tal cuenta cómo Norbert Hanold se concentra en el pie y en el movimiento de una joven que aparece en un bajo relieve que él denominará Gradiva. Es tal su fijación, que se inventa una historia para la joven del grabado, seguro de que esta habría muerto en la famosa erupción de Pompeya y decide ir a buscarla. Más allá de la diégesis de la novela propiamente, lo crucial para este trabajo es el delirio del personaje a partir de la fijación de una parte del cuerpo (el pie), y la manera en que a partir de ella es capaz de imaginar y construir no solo la identidad de su amada, sino de alucinar y tener encuentros con la joven. Claro que, como dice Barthes, Hanold es un enamorado excesivo porque alucina lo que otros solo evocan (Barthes 1996: 145).

De forma similar, es pertinente establecer un vínculo con varios de los postualados barthesianos en Fragmentos de un discurso amoroso, ya que, y esto es notable, el verdadero objeto del enamorado excede al amado o a la amada, lo cual le ocurre tanto a Hanold como al protagonista de los Jardines secretos de Mogador:

\footnotetext{
Anulación: Explosión del lenguaje en el curso del cual el sujeto llega a anular al objeto amado bajo el peso del amor mismo: por una perversión típicamente amorosa, lo que el sujeto ama es el amor, no al objeto. (Barthes 1996: 39)
}

Pero entonces, antes de continuar, se requiere delinear la falta y el deseo, ya que no solo intervienen directamente en la construcción del sujeto, sino y sobre todo porque tal es el origen del discurso del enamorado que luego se escenificará en la novela.

El niño, para Freud, se encuentra en completud antes de nacer, sin falta y sin deseo, pero al no estar más en el vientre materno sobreviene la carencia. En ese momento, el niño desea la unión total con su madre y así su madre se convierte en su objeto de deseo, esto es el objeto perdido. Y es que por si fuera poco, por lo general, la madre se encarga de satisfacer todas las necesidades del niño. Por eso, el niño ve en su madre la satisfacción de sus deseos y gusta de sus caricias, de cuando ésta lo alimenta y del momento en que ésta lo limpia, ahí sobreviene el complejo de Edipo:

[El complejo de Edipo es el] conjunto organizado de deseos amorosos y hostiles que el niño experimenta respecto a sus padres. En su forma llamada positiva, el complejo [de Edipo] se presenta como en la historia de Edipo Rey: deseo de la muerte del rival que es el personaje del mismo sexo y deseo sexual hacia el personaje del sexo opuesto. (Laplanche 1996: 61-66)

Cuando esta relación diádica de perfecta identificación ente el niño y la madre comienza por resquebrajarse debido a que el niño se percibe distinto de ella, es lo que Lacan llama la fase del espejo (Lacan, Seminario IV) fundante del deseo. Esta es la primera pérdida que será revivida una y otra vez por el sujeto. Aquí es posible de nuevo traer a colación a Barthes, quien al respecto indica que:

[...] el hábito de estar separado de mi madre -lo que no dejó, sin embargo, de ser doloroso (por no decir enloquecedor). Actúo como un sujeto bien destetado, sé alimentarme, mientras espero, de otras cosas que no vienen del seno materno. (Barthes 1996: 46)

En este sentido, toda relación amorosa es una representación, una vuelta a poner en escena la pérdida del objeto, la carencia, la ausencia de la madre. Ello resulta determinante en nuestro análisis porque como se verá es ante la carencia que el narrador de la novela que nos 
ocupa se lanza a la búsqueda de los jardines imposibles para complacer el deseo y la demanda de su amada y así poder asirla, de igual forma que el personaje de la Gradiva, Hanold, siente este deseo por su amada imaginaria, como explicara Freud en su lectura.

Ahora bien, continuando las aclaraciones teóricas, debe indicarse que, según Lacan, para evitar el incesto aparece la prohibición del Padre, y es así como se inserta al sujeto en el registro de lo Simbólico, en el lenguaje, que es lo mismo que decir que el sujeto ya escindido queda atrapado en la red cultural e ideológica, y es así como clausura el Edipo:

\begin{abstract}
[...] Lacan introduce el concepto de falo, como un objeto nuevo, distinguido y privilegiado como principal objeto narcisista. El falo, ¿qué es? Miller lo plantea como el heredero del narcisismo freudiano. El soporte esencial de la libido del yo, transfusión a libido de objeto. Se plantea en este Seminario (de Lacan) que la relación madre-hijo no existe, ésta se encuentra atravesada por el falo. Y no sólo atravesada por el falo, sino a su vez, por otras dos instancias: la relación de la madre con su falta y por la función paterna. Y el niño viene a situarse en la madre en una relación directa con su falta. (Chacón 1997: 126)
\end{abstract}

Debido a lo anterior, el sujeto es siempre deseante, siempre carente, siempre incompleto. $\mathrm{Y}$ es que sobre el tema de la completud vale incluir a Nietzsche, quien se refería al problema de la completud en estos términos:

\begin{abstract}
No creemos que la verdad continúe siéndolo si se le arranca el velo (que la cubre)... para nosotros es cuestión de decoro no querer verlo todo desnudo, no querer asistir a todas las cosas, no pretender comprenderlo y saberlo todo. ¿Es verdad que Dios ve todas las cosas? - Preguntaba una niña a su madre. -¡Por supuesto! -Y la niña respondía: Yo considero esto indecente. ¿Qué lección para los filósofos!” (Nietzsche 2001: \&4, 69)
\end{abstract}

Es así como la totalidad, el absoluto, la completud son propiedades de Dios y por eso mismo ajenas y obscenas (en el sentido etimológico del termino: fuera de la escena del lenguaje) para el ser humano; hasta pudiéramos decir monstruosas, siniestras o unheimlich, porque el cumplimiento de todos los deseos genera envidia de los dioses, en palabras de Freud (2003: 239). Y es que lograr el objeto deseado rompe con todo el sistema psíquico según el cual el sujeto ha sido conformado, y este zozobra: cuando la falta falta, el sujeto zozobra, decía Manuel Picado en sus clases de psicoanálisis. Es lo que, a su vez, Lacan identificará como el encuentro con lo Real.

En ese orden de ideas, amerita puntualizar que la mirada del objeto tampoco puede ser completa, aunque así lo queramos, por muchas razones: desde nuestra mortalidad, hasta nuestra subjetividad, e incluso, según la cita anterior sobre Lacan, el deseo aparece ante la pérdida del objeto (la madre) que siempre se escribe como objeto perdido, de modo tal que la completud es de base imposible, porque somos sujetos y como tales somos incompletos, carentes.

Debo detenerme aquí aún más pues la mirada es para Lacan uno de los soportes de la pulsión, que siempre resulta real y ominosa porque es indecible. Y es que resulta crucial tomar en cuenta que es la mirada de la madre la que le hace creer al niño la completud, antes de la fase del espejo, ella es el espejo del niño en su mirada:

El niño al verse reflejado en los ojos de la madre, y ser ella su propio espejo, la completa. [...] No hay falta entre ambos. [...] A través de la mirada materna, el infans recibe una sensación de completud, de acabamiento, que permite unificar su cuerpo, al que sólo percibe como fragmentado. (Baudes 1995: 28-29)

Ante esa carencia, por su parte, aparece el deseo. Se trata de buscar el objeto perdido para recuperarlo (principio del placer -Eros- y pulsión de muerte -Thanatos-) aunque su recuperación implicaría un encuentro con lo real y la zozobra del sujeto. Dado que el sujeto es incompleto, y su objeto de deseo es movible, porque aunque lo perdido siempre es la madre se representa de formas diferentes, como sucede con la palabra que está en lugar de la cosa, así el 
sujeto enamorado cree que su objeto de deseo lo completará, pero lo ve desde su incompletud y por eso lo fragmenta y hasta lo sustituye, sea con otro objeto que de forma metonímica se identifique con el objeto de deseo o, incluso, con una parte del cuerpo solamente. Al respecto apunta Freud:

\begin{abstract}
El objeto sexual normal es sustituido por otro relacionado con él, pero al mismo tiempo totalmente inapropiado para servir al fin sexual normal. [...] El sustitutivo del objeto sexual es, en general, una parte del cuerpo muy poco apropiada para fines sexuales (los pies o el cabello) o un objeto inanimado que está en visible relación con la persona sexual, y especialmente con la sexualidad de la misma (prendas de vestir, ropa blanca). [...] El caso patológico surge cuando el deseo hacia el fetiche se fija [...] y se coloca en lugar del fin normal o cuando el fetiche se separa de la persona determinada y deviene por sí mismo único fin sexual. (Freud 1981: 1182, 1183)
\end{abstract}

Tal es el caso de la Gradiva, y como se verá también del protagonista de Jardines secretos de Mogador, pues mientras uno sustituye su deseo con la imagen de los pies de un bajo relieve, el otro será cautivado por diversas partes del cuerpo de Jassiba, su amada pero, más aún, una vez que ella lo rechaza y le demanda el cumplimiento de su deseo, él opta por ir en busca de los jardines secretos que funcionarán entonces como metonimia del objeto perdido, Jassiba, que a su vez es metonimia de la madre. No es casual que, recordemos, Jassiba esté embarazada y, por ello efectivamente, ya es concebida como madre para su amado.

Esto ocurre tal y como explica Freud debido a que:

Todo objeto tocado por el cuerpo del ser amado se vuelve parte de ese cuerpo y el sujeto se apega a él apasionadamente. [...] Tan pronto el objeto metonímico es presencia (engendrando alegría) como ausencia (engendrando desamparo). (Freud 1981: 1182, 1183)

Al respecto Barthes establece la clave para este estudio y es la figura del cuerpo del otro, según lo cual el cuerpo se define no tanto en el sentido del cuerpo físico como tal si no que como:

Todo pensamiento, toda emoción, todo interés suscitados en el sujeto amoroso por el cuerpo amado. Su cuerpo estaba dividido: por una parte, su cuerpo propio -su piel, sus ojos-, tierno, cálido, y por la otra, su voz, breve, contenida, sujeta a accesos de distanciamiento, su voz, que no daba lo que daba su cuerpo. O incluso: por un lado su cuerpo mullido, tibio, justamente suave, afelpado, jugando con la timidez, y por el otro, su voz -la voz, siempre la voz- sonora, bien formada, mundana, etc. (Barthes 1996: 80)

Y es que como se verá, el enamorado recorre el cuerpo del otro, como explorándolo, como tratando de entender aquello que le provoca toda esa fascinación, todo ese sentimiento, todo ese amor. Así las cosas, mejor adentrémonos de lleno en el jardín.

\title{
4. Jardines en el discurso amoroso sonámbulo
}

Para terminar de explorar los elementos de este jardín que se construye gracias al discurso amoroso, como he venido indicando, la novela es compleja y, de hecho, responde a la lógica del ensamble (Abeyta 2007: 14), donde no solo se está ante el texto por demás de alta carga poética, sino que imágenes, caligrafías, y hasta citas de refranes y otros autores como Shakespeare o André Guide entran en juego y dialogan. Esto sucede de forma muy natural, y no se percibe gratuito o forzado. Y es que el lazo que une a todos estos elementos es el deseo de ambos personajes, pero más aún el recorrido que se hace de la ciudad de Mogador.

Mogador que, siendo la ciudad del deseo, no solo es el locus perfecto para esta historia de amor, si no que funciona como metáfora del cuerpo de Jassiba, pues es como si al recorrer Mogador se recorriera el cuerpo de Jassiba, en la medida en la que Barthes hablaba 
de exploración del cuerpo del otro. Se obtiene así una primera unidad connotativa: la ciudad cuerpo. Esto sucede ciertamente no solo por lo ya dicho sino que además, el protagonista narrador, es decir el enamorado es un viajero de Mogador que accede a lugares secretos, esto es: conoce íntimamente la ciudad. Es tal la fuerza de esta que, de hecho, desde el inquipit, se manifiesta este recorrer del cuerpo que es un recorrer por la ciudad:

\footnotetext{
[...] Era en Mogador la hora en que los amantes despiertan. Todavía traen los sueños enredados en las piernas, tras los ojos, en la boca, sobre las manos vacías....

Era en Mogador la hora en que todas las voces del mar, del puerto de las calles, de las plazas, de los baños públicos, de los lechos, de los cementerios y del viento se anudan, y cuentan historias. (Ruy Sánchez 2002: 15)
}

Queda así establecido desde el primer momento de la lectura este paralelismo que tendrá que seguir el lector acompañando al narrador en primera persona, al enamorado, en su viaje por la ciudad y por el cuerpo de su amada, hacia el deseo, en busca de los jardines, en busca de las historias. Se construye, entonces, esa relación cuerpo/ciudad/texto que irá tomando forma a lo largo de la novela, como un trazado de un mapa, como una cartografía:

\begin{abstract}
Así quisiera yo trazar en tu piel, Jassiba, la geometría secreta de nuestro paraíso. Una figura que sólo tú pudieras ver y descifrar en un lenguaje inventado por nuestros cuerpos [...] Quiero ser en tu piel la línea escrita de la felicidad. [...] Quisiera ser la jena que te cubre y que viene de ese lugar fuera del mundo que por un instante compartimos. (Ruy Sánchez 2002: 83-4)
\end{abstract}

Más adelante, también podemos, ya de forma más concreta, referirnos a la idea del laberinto que ya habíamos anunciado como parte de los elementos que ayudan a anudar la novela, y es precisamente el momento en que el enamorado conoce a Jassiba:

\footnotetext{
En Mogador siempre hay plazas dentro de las plazas, calles dentro de otras y tiendas dentro de tiendas hasta llegar a las cajas de maderas incrustadas (taraceadas) más pequeñas, que en sus compartimentos interiores de marquetería pueden albergar, en miniatura, la esencia de un mercado y hasta de un bosque: sus olores... (Ruy Sánchez 2002: 25)
}

Así, el cuerpo/ciudad/texto que se va develando a lo largo de la lectura es ahora también laberinto con una condición fractal. Ahí, él la sigue y ella "suavemente se fue metiendo en el laberinto" (26), dice.

Después de seguirla y que ella lo sedujera aparentemente vendiéndole flores solo con pétalos de estas, en un claro acto metonímico, hecho que luego sabremos ha sido malinterpretado por el enamorado, y en realidad ella estaba llevando a cabo un ritual para lidiar con la muerte de su padre, manifiesta dos aspectos que interesan para el análisis que estamos llevando a cabo. Primero:

No me daba cuenta de que ella estaba dejando crecer en mi fantasía todo lo que yo deseaba en ese momento. (Ruy Sánchez 2002: 27)

A partir de lo anterior, podemos establecer la correlación con la Gradiva de Freud, donde el enamorado en realidad está creando una fantasía que responde a sus deseos. Y además:

Más tarde me explicó la compleja geometría de sus tatuajes en las manos. Hizo que mis dedos recorrieran los
caminos pintados sobre su piel y simuló, como una de sus uñas, que dibujaba algo en las mías. Pero mientras
hacía eso en mi mano, algo más dibujaba dentro de mí que ya nunca se borraría. (Ruy Sánchez 2002: 27)

En relación con lo anterior, se puede remitir a la figura contactos que descubriera Barthes o como él dice: "todo discurso interior suscitado por un contacto furtivo con el cuerpo (y más precisamente la piel) del ser deseado" (1996: 74). 
Asistimos, después, a un momento cumbre, en el cual el enamorado observa a Jassiba hacer el amor con el sol y descubre que el deseo de ella es otro, la ve como una imagen de la que él no es parte, y empieza a tomar conciencia de que su amada se le escapa:

Un día la sorprendí sentada cerca de su ventana, ofreciendo su piel al primer sol del día. Los pies primero, luego las piernas y más tarde la madeja de su pubis, que ella miraba como si fuera, un arbusto, un bosque un sembradío... (Ruy Sánchez 2002: 20)

Esto es importante porque en el discurso del sujeto enamorado esto es tipificado por Barthes a partir de las figura de las imágenes:

La imagen se destaca; es pura y limpia como una letra: es la letra de lo que me hace mal. Precisa, completa, acabada, definitiva, no me deja ningún lugar: soy excluido de ellas como de la escena original, que no existe quizás sino por lo mismo que el contorno de la cerradura la destaca. He aquí pues, la definición de la imagen: la imagen es aquello de lo que estoy excluido. (Barthes 1996: 154)

Siguiendo esta línea de pensamiento, es posible entonces ir comprendiendo el discurso del protagonista como el discurso del enamorado que además de ver la imagen de su amada escapársele, reitera la fragmentación del cuerpo de la amada, y esto ocurre por cuanto hay una imposibilidad de abarcarla toda, en tanto como ya explicamos la mirada enamorada fragmenta.

Y este momento representa la catástrofe para nuestro enamorado ya que Jassiba a partir de ahí le resultará ajena e incomprensible. Él mismo confiesa que ante su incapacidad de entenderla, intentó equipararse con el sol, intentó hacer le el amor como el sol, pero al no poder cumplir optó por hacer bromas sobre el hecho. La reacción fue un profundo resentimiento de parte de ella "fue germinando en su piel la sensación de no ser comprendida", hasta que entonces sobrevino el reto (Ruy Sánchez 2002:21).

Otros puntos fundamentales necesarios de recapitular son, por un lado, esos tatuajes que cubren la piel de Jassiba y que sirven tanto para vestir como para desvestir, según nos dice su enamorado y de cómo el cuerpo es también texto para el enamorado, ya no solo porque leemos su camino por el mapa de este cuerpo/ciudad/laberinto, sino porque el cuerpo de Jassiba posee una escritura literalmente, porque él la irá reconociendo y reescribiendo conforme vaya descubriendo los jardines secretos. Y es que el enamorado siempre escribe ante la falta de su objeto de deseo, como señala Barthes (1996: 45).

Y por otro lado, está la conexión con los jardines, que además de ser lo que Jassiba le pide al enamorado que descubra para ella, es además el lugar donde se produce todo el enamoramiento del protagonista y Jassiba, pues ella lo lleva a su jardín interno, del cual en la novela se indica que:

\footnotetext{
Significa, para comenzar, jardín interno, un reducto de naturaleza dentro de una casa. Por extensión se llama Ryad a la casa misma si incluye un patio con plantas. También se dice de cualquier morada urbana que sea un remanso inesperado en la agitación de las calles. Un Ryad en la ciudad es como un oasis en el desierto. Ryad es por supuesto uno de los nombres del paraíso. (Ruy Sánchez 2002: 28)
}

De esta forma, y por obra y gracia de la magia literaria el cuerpo/ciudad/texto/laberinto es ahora también este jardín, este Ryad que al ser paraíso cumple todos los deseos, porque en el paraíso no hay falta. Nuestro enamorado entró en el Ryad de Jassiba, y ahí vivieron un idilio como sonámbulos (aquellos que viven solo para su deseo, se dice la novela) (2002: 52-53), pero luego fue expulsado del paraíso al cometer la falta de no comprender a su amada y no ser capaz de cumplir con todos sus deseos. Por ello, es lanzado en la búsqueda de ryads secretos por todo Mogador, que es la ciudad del deseo, tal y como nos lo anunciara él mismo, al inicio de la novela. 
Y así, finalmente, se logra identificar la ecuación según la cual se organiza este texto, y es posible afirmar, entonces, que el texto se corresponde con el cuerpo de la amada, que es paraíso y resuello donde todos los deseos del enamorado se cumplen, y que dicho cuerpo/texto se fragmenta por la imposibilidad de mantener la completud, en tanto todos somos sujetos carentes. Pero, más aún por cuanto el enamorado es expulsado como Adán de este paraíso (y en esa dimensión, es que debemos considerarlo carente), y así, adicionalmente, se conforma el texto como un laberinto, donde el enamorado tratará ya no de salir sino de recorrer, adentrándose cada vez más, buscando los jardines para su amada. Por último, en este viaje por Mogador que es también el cuerpo de Jassiba (y el texto, y el jardín), el enamorado va además escribiendo y el lector leyendo, también en fragmentos, como el cuerpo de la amada.

\section{Bibliografía}

Abeyta, Michael. 2007. "Catedrales, nómadas y cuerpos sin órganos: Entre Gilles Deleuze y las novelas de Mogador de Ruy Sánchez”. Revista Iberoamericana. 73 (218): 13-27.

Barthes, Roland. 1996a. El placer del texto. ( $9^{\text {a }}$ ed.). Madrid: Siglo XXI. 1996b. Fragmentos de un discurso amoroso. (12 ${ }^{\mathrm{a}}$ ed.). Madrid: Siglo XXI.

Baudes de Moresco, Mercedes. 1995. Real, Simbólico, Imaginario. Una introducción. Buenos Aires: Letra viva.

Chacón, Laura. 1997. "Medea: Historia de una mirada”. Inscribir el psicoanálisis. 4 (7). Costa Rica: Porvenir.

Chevalier, Jean y Alain Gheerbrant. 1999. Diccionario de los símbolos. (Trad. Manuel Silvar y Arturo Rodríguez). ( $6^{\mathrm{a}}$ ed.). Barcelona: Herder.

Freud, Sigmund. 1981. "Tres ensayos de sexualidad". Obras Completas. Vol. II. (4 ed.). Madrid: Biblioteca Nueva.

2003. "Lo ominoso (1919)". Obras Completas. Vol. XVII. (2 ed.). Buenos Aires: Amorrortu.

Laplanche, Jean y Jean-Bertrand Portalis. 1996. Diccionario de Psicoanálisis. Barcelona: Paidos.

Nietzsche, Friederich. 2001. "Prefacio". La Gaia Ciencia. (Trad. German Cano). (2a ed.). Madrid: Biblioteca Nueva.

Sánchez Ruy, Alberto. 2002. Los jardines secretos de Mogador. Voces de tierra. México: Alfaguara.

2000. "Escribir en las fronteras del cuerpo". En: Angel Fire.com. Recuperado de: http://www.angelfire.com/ar2/libros/Escribirenlas1.html. Consulta: 22 de setiembre de 2012. 